\title{
A field study, laboratory test and cost estimation of solid and liquid lubricants in directional wells to reduce friction coefficient and improve ROP
}

\author{
Ali Fereidounpour ${ }^{1} \cdot$ Mohammad Javad Sarbaz Hosseini $^{2}$
}

Received: 7 January 2020 / Accepted: 6 July 2020 / Published online: 11 August 2020

(c) Springer Nature Switzerland AG 2020

\begin{abstract}
Drilling fluid is being used to facilitate drilling operation from the surface to a target formation. Due to the complexity of well geometry in directional drilling operations and high torque and drag forces, minimizing the coefficient of friction (CoF) is important. Excessive torque and axial drag cause mechanical erosion on the drill string, which ultimately leads to fatigue, wash out and twist off. Field data for 9 wells in one of the Iranian oilfields showed that slide drilling was practically impossible beyond $4000 \mathrm{~m}$ due to the unexpected high torque and drag during directional drilling despite the presence of liquid lubricants in drilling fluid at concentrations up to $5 \mathrm{vol} \%$ as per drilling program. Based on the results, the primary source of torque and drag in the wells with proper hole conditioning is sliding friction. Using different types of lubricant in drilling fluid system is the most practical methods to reduce the drag force (sliding friction) caused by the contact between drillstring and well casing or borehole. This paper investigates the effect of solid and liquid lubricants on the $\mathrm{CoF}$ in laboratory and field applications. Based on the successful implementation, a specific instruction was designed for the use of glass bead as a solid lubricant in drilling fluid to reduce the CoF. Cost estimation indicates that compared to the liquid lubricants, solid lubricants can reduce drilling fluid costs significantly. Moreover, based on Experimental results, no more than 5-6 percent of liquid lubricants can be used to reduce friction coefficient. This limitation, along with the issue of lubrication regimes, leads us to use solid lubricants. Laboratory and field test results showed that addition of glass bead as a solid lubricant can improve the performance of water-based drilling fluids as evidenced by improvement in ROP up to $240 \%$ (average ROP: $160 \%$ ).
\end{abstract}

Keywords Solid lubricants · Liquid lubricants · Torque and drag reduction · Friction coefficient

\section{Introduction}

In drilling industry, directional and horizontal intervals are being designed and drilled for different reasons such as avoiding sensitive surface sites, reducing costs by drilling several wells from one surface location, better reservoir drainage and increasing oil and gas production $[2,8]$. Axial drag force and rotational torque caused by friction between drillstring and drilling fluid as well as wellbore wall, are among the important concerns associated with deviated and horizontal drilling [11]. Tight hole condition, differential pressure sticking, high dogleg severity and key seats, sloughing formations and stuck pipe and poor hole cleaning could cause excessive torque and drag in the wellbore. Slide drilling is implemented using a downhole motor, while the drill pipe slides along the wellbore without rotating. To initiate slide drilling, directional driller should orient the bit in alignment with the trajectory proposed in the drilling program. It means that drilling is stopped and the drill bit (or drillstring) is pulled off-bottom

$\square$ Ali Fereidounpour; Mohammad Javad Sarbaz Hosseini, sarbazhosseini_m@mapnadrilling.com | 'Institute of Petroleum Engineering, University of Tehran, Tehran, Iran. ${ }^{2}$ Mapna Drilling Company (MDCO), Tehran, Iran. 
and the string is reciprocated to release drag that might have been built up within the drill string. The drag force influences on weight on bit (WOB) and is responsible for the difference between the actual WOB and the WOB applied by easing the brake at the surface.

Extreme torque and drag, especially unplanned, can be detrimental to drilling operations. Over the years, engineers have developed numerous ways to challenge the drilling limitations by reducing torque and drag forces in order to drill further and deeper. The different torque and drag reduction methods are listed below.

\section{Wellpath design}

2 Light weight string components

3 Lubricants (liquid and solid)

4 Hole Cleaning

5 Co-polymer beads

6 Mechanical friction reduction tools

7 Increased drill string and rig capability

Using beads (solid lubricants) is a mechanical way to reduce the coefficient of friction. Beads are inserted between the drill string and bore hole to reduce the coefficient of friction. It does not affect the chemical characteristic of the mud system [10].

The most common way to reduce torque and drag is the use of oil-based mud (OBM) or synthetic-based drilling fluids instead of water-based mud. but on the other hand, the used of OBM is not always applicable or tends to be avoided due to different reasons, such as negative effects of exposing the reservoir to OBM for example, or challenges in high temperature applications. The longest well drilled in this study (project) was safely delivered by using OBM, but different torque reduction techniques were needed in order to drill wells with similar complexity but using WBM, therefore; different mud lubricants were evaluated together with the used of torque reduction subs. Extensive testing was carried out in order to evaluate different lubricants to be used with water-based drilling fluid. A kind of lubricant had shown excellent results in lab testing phase and it showed the potential to significantly reduce torque and drag while maintaining the highest film strength among the other options under consideration. This lubricant was used in the well, starting with a $2 \%$ concentration by volume, and maintaining a concentration of up to $4 \%$ while drilling the 6 in hole section. The results showed the improvement in terms of drag reduction, friction factor for pick up loads decreased from 0.35 to 0.22 in average, and from 0.22 to 0.1 for slack offs [13].

A novel lubricant based on biodiesel was introduced and have been used in water-based drilling fluids [14]. The results suggested that the lubricant has great performances in different water based drilling fluids (WBDFs).
Its performance became even better after hot-rolling at $150^{\circ} \mathrm{C}$ for $16 \mathrm{~h}$. In addition, the performances of the lubricant mixed with some other lubricants including zinc dialkyl dithiophosphate (ZDDP) and modifiedgraphite (MG) in WBDFs were investigated. The results showed that the lubricity can be further enhanced by some synergetic effects between different lubricants.

In complex well profile, a different solution, like the new generation mechanical lubricant is an algue-based powder lubricant (light yellow in color) comprised of microscopic encapsulations. Each encapsulation is between 5 and 10 microns, and each cell contains pure lubricating oil. When added to mud system, the powder remains dispersed in the fluid and does not deply its pure lubricating oil until it is exposed to mechanical and operational shear. At that point, it provides targeted lubrication, exactly where friction between surfaces (which actually creates the high torque and drag) creates a sufficient pressure to crash the encapsulation [12].

None of the liquid lubricants lowered the friction coefficients to levels expected of oil-based muds. However, the most effective additives for lowering the CoF value were the derivatized water-soluble esters and the emulsifier/alkaline surfactants [1].

Solid lubricants act much like ball bearings. These materials interfere with the contact surfaces without bonding to them. Because they do not bond, the performance of these lubricants is usually independent of mud type. Round, incompressible particles are imbedded in the wall cake and provide a load-bearing surface between pipe and wall. The beads may create a small standoff distance for pressure transmission and flow as well. This standoff and point contact may reduce the overall frictional surface area.

Liquid lubricants, on the other hand, form a film that is thick enough to mask surface roughness and strong enough to withstand high compressional forces. Because liquid lubricants compete with other surface-active components in the drilling mud, their performance tends to depend on their concentration. In addition, at high shear rates, these lubricants can become tightly emulsified and so stable that adsorption is inhibited. The nature of the mud and the contact surfaces can greatly affect the lubricity imparted by an additive. Thus, some products that are effective in clay-based muds are less effective in polymer-based muds [3].

Liquid lubricants are heavily influenced by downhole temperature and pressure, and cannot provide the desired lubricating properties needed in all conditions. according to research conducted on lubrication regimes, a lubrication mechanism should be designed that includes solid and liquid lubricants [9]. 
In all mentioned studies, only the effect of solid or liquid lubricants on drilling fluid has been investigated, while in many cases in drilling, the use of liquid and solid lubricants is required simultaneously. Therefore, it is necessary to consider a suitable combination of them. It means that a specific instruction should be designed for the use of glass bead as a solid lubricant in drilling fluid to reduce the CoF. Moreover, based on Experimental results, no more than 5-6 percent of liquid lubricants can be used to reduce friction coefficient. This limitation, along with the issue of lubrication regimes, leads us to use solid lubricants (glass beads).

Nine wells were drilled in the oilfield indicating that slide drilling would be practically impossible beyond $4 \mathrm{~km}$ in $6 \frac{1}{8}$ inch hole section due to the excessive drag and torque. Geological information and drilling program were similar for all nine wells. These wells were drilled and all of them have a horizontal interval inside the reservoir formation to provide maximum drain hole for oil production. The purpose of this paper is to investigate the effect of different lubricants on the drag and torque in horizontal wells. Different sizes of glass beads as solid lubricants can reduce the CoF and increase the lubricity required to extend the length of horizontal intervals.

\section{Methodology}

\subsection{Drilling program summary}

After cementing the 7-inch liner and confirmation on of its proper cementing, $6 \frac{1}{8}$ inch horizontal section was drilled from depth 2700 to $4300 \mathrm{~m}$ by the use of a polymer mud system containing potassium chloride $(\mathrm{KCL})$ and Partially Hydrolyzed Polyacrylamide (PHPA) with a mud weight of 78 PCF (Pound Per Cubic Foot). Table 1 shows the drilling fluid properties for drilling $6 \frac{1}{8}$ inch section.

According to the drilling plan, logging while drilling (LWD)/measuring while drilling (MWD)/gamma ray (GR) were run in the directional open hole and a string of $4 \frac{1}{2}$ inch perforated liner was run and hung off. Based on the data from offset wells, the potential risks of drilling $6 \frac{1}{8}$ inch

Table 1 Drilling fluid properties for drilling $6 \frac{1}{8}$ inch section

\begin{tabular}{ll}
\hline Properties & Value \\
\hline Density (PCF) & 78 \\
Viscosity (Sec) & 44 \\
Plastic Viscosity or PV (CP) & 15 \\
Yield Point or YP (lb/100 ft ${ }^{2}$ ) & 21 \\
Fluid Loss (cc/30 min) & 4 \\
PH & 10.5 \\
\hline
\end{tabular}

section include high drag force, fluid loss, tight hole and stuck pipe. In case of having a problem with Shale layers 3-5 wt \% of KCL and PHPA should be added to the system to minimize the associated problem. It is necessary to adjust mud weight and mud properties to ensure a proper hole condition.

During drilling the interval, in addition to having low Rate of Penetration (ROP), several tight hole situations, as well as kicks were encountered. in this section of the borehole. polymeric viscosity modifiers were used to provide viscosity and cutting transport capacity and starch to reduce mud filtrate [5]. In the directional and horizontal sections, a pre-specified amount of liquid lubricant will be added to the active system to minimize torque and drag. As mentioned, the data from the offset wells suggest the high probability of high torque and drag during slide drilling of 9 wells with the same trajectory in this oilfield to the point that sliding drilling becomes practically impossible due to the rotational torque and axial drag.

All the possible causes for the problem including mud motor failure, poor hole cleaning, tight holes, and well trajectory (surveys) were studied until the real cause of the problem (failure of liquid lubricant in providing enough lubricity) was identified. For this purpose, the effects of solid and liquid lubricants on friction coefficient are investigated in the laboratory.

\subsection{Lubricants}

Lubricants can be divided into two types: solid and liquid. For many years the oil and gas industry has used liquid lubricants in the directional drilling operation $[4,6]$. Many liquid lubricants have been developed to reduce CoF. The liquid lubricants are being used in drilling fluid based on their performance criteria (CoF reduction), compatibility with drilling fluid and other additives, as well as their cost and their compliance with the local and federal environmental regulations.

Lubricants reduce weight stacking in highly deviated wellbores, allowing the transfer of more weight to the bit. This increases ROP, decreases torque and drag and minimizes problems tripping in and out of the hole in drilling. In addition to friction reduction, it also reduces the amount of wear that occurs during operation, reduces operating temperatures and minimizes corrosion of metal surfaces. Liquid lubricants form a film between the two surfaces contact and reduce friction by preventing sliding contact interfaces from severe or more frequent drill string-well casing or tool joint-borehole contacts.

Liquid lubricants are heavily influenced by downhole temperature and pressure, and cannot provide the desired lubricating properties needed in all conditions. They also effect on rheological properties of drilling mud. In 
addition, according to research conducted on lubrication regimes, a lubrication mechanism should be designed that includes solid and liquid lubricants.

Solid lubricants such as glass beads act as tiny ball bearings and they become embedded in the filter-cake and provide a low friction bearing surface. The glass beads are chemically inert and do not affect the chemical characteristic of the mud system. They will not break under downhole extreme stress and impact. The size of the beads ranges from fine grade to coarse grade classes. Instead of having metal to metal contact during the drilling operation, the drill string slides down the borehole, rolling on the beads.

Glass beads are mainly applied to the build section of hole where the forces accumulate. The method is to use glass beads in the build section, the beads slowly embedded in mud cake while move up and down string. As they settle on the low side of the annulus, the beads ultimately reduce the torque and drag forces and improve weight transferring to bit.

\subsection{Experimental materials}

Three types of liquid lubricants were studied: Lub A, Lub $B$ and diesel oil (Table 2). These kinds of lubricants have been used in mentioned wells. Lub $A$ is a highly water dispersible, and completely miscible with all types of drilling fluids. It usually reduces the friction coefficient of the wall cake and lessens the possibility of the differential sticking.

Lub $B$ is an oil-soluble blend of natural oil types and modified oils formulated for water-based drilling fluids to use as a lubricant and minimize torque and drag, especially in directional drilling. Lub $B$ disperses easily in any mud system and is compatible with all the common waterbased additives. It does not adversely increase rheological properties and usually causes a beneficial decrease in fluid loss.

Diesel oil is another liquid lubricant. Diesel oil is the most widely used lubricant in the drilling industry. The use of diesel oil is mainly done to improve the rheological properties and control filtration loss, promote lubrication while drilling and minimize the problems associated with stick pipes. The most important physical properties of microspheres for oil field applications are collapse strength and specific gravity of the material [7].

\subsection{Experimental procedures}

According to Table 3, numerous saturated NACL/KCL/ PHPA/ polymer mud samples were made and used as the base mud for this suite set of tests. The liquid lubricants (Lub A, Lub B, and diesel oil) was added at 1,2 and 3 vol\% in combination that is a typical concentration range for field applications. Also, diesel oil was added at 1, 2, 3, 4 and 5 vol\% separately and API fluid loss test was conducted. The filter cake was then put on Friction Coefficient tester (Figs. 1 \& 2). The effect on friction coefficient was measured using the NZ-3A Friction Coefficient apparatus. Then solid lubricant (Glass Bead 100 \& 600) was added at 0.1, 0.3 and $1 \mathrm{lb}$ per barrel to every samples and effect on friction coefficient was measured again. GB 100 and GB 600 referred to Glass beads with an average particle size of 100 microns and 600 microns respectively (Table 4).

\subsection{Friction coefficient tester construction and working principle}

Friction Coefficient of mud cake is very important to the behavior of directional Bottom Hole Assembly (BHA), especially in highly deviated wells. The Friction Coefficient measurement can be conducted and measured with Friction Coefficient tester model NZ-3A, reliable with the high

Table 3 Base mud composition

\begin{tabular}{ll}
\hline Additive name & Concentration $(\mathrm{lb} / \mathrm{bbl})$ \\
\hline Drill water & 320 \\
Sodium chloride & 45 \\
Potassium chloride & 16 \\
Caustic soda & 1 \\
Soda ash & 1.5 \\
Starch & 10 \\
Polyanionic cellulose (PAC) & 2 \\
PAC (ultra) & 0.7 \\
XC polymer & 0.7 \\
Liquid lubricants & As specified \\
\hline
\end{tabular}

Table 2 Liquid lubricants properties

\begin{tabular}{lllll}
\hline Lubricant type & $\begin{array}{l}\text { Specific gravity (at } \\
\left.20{ }^{\circ} \mathrm{C}\right)\end{array}$ & Pour point $\left({ }^{\circ} \mathrm{C}\right)$ & Flash point $\left({ }^{\circ} \mathrm{C}\right)$ & $\begin{array}{l}\text { Cost (55 } \\
\text { Gallons) } \\
(\$)\end{array}$ \\
\hline Lub A & $0.8-1$ & Less than -10 & More than 100 & 680 \\
Lub B & $0.9-1$ & Less than -10 & More than 100 & 530 \\
Diesel oil & $0.84-0.86$ & Less than 0 & $80-94$ & 0.25 \\
\hline
\end{tabular}




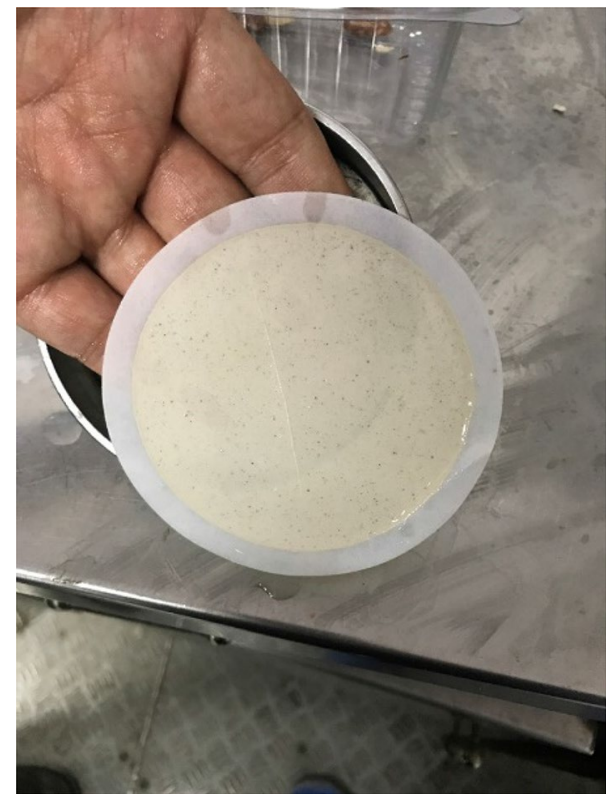

Fig. 1 Thin filter cake

Fig. 2 NZ-3A lubricity test apparatus

Table 4 Solid lubricants properties

\section{(}

accuracy with a simple structure. The Friction Coefficient tester produces an indication of the mud cake resistance against a sliding board. The apparatus is composed of a body cover a sliding board, a digital indicator, a driving device and a micro motor. The apparatus is portable. Made of anti-corrosion stainless steel, the sliding block and the sliding bar are general parts for testing. The sliding board is precisely made of Teflon. The level spirit indicators are installed on both the upper and lower sides of the sliding board and one side with the groove; it is a working table for testing. Under the conditions of its tilting on the sliding board, functioned with the downside gravity the sliding block placed on the mud cake begins sliding after overcoming the friction force.

\section{Results and discussion}

\subsection{Laboratory results}

The Friction Coefficient test results are shown in Table 5 and Figs. 3, 4 \& 5). The lubricity of basic mud before lubricant was added was evaluated.

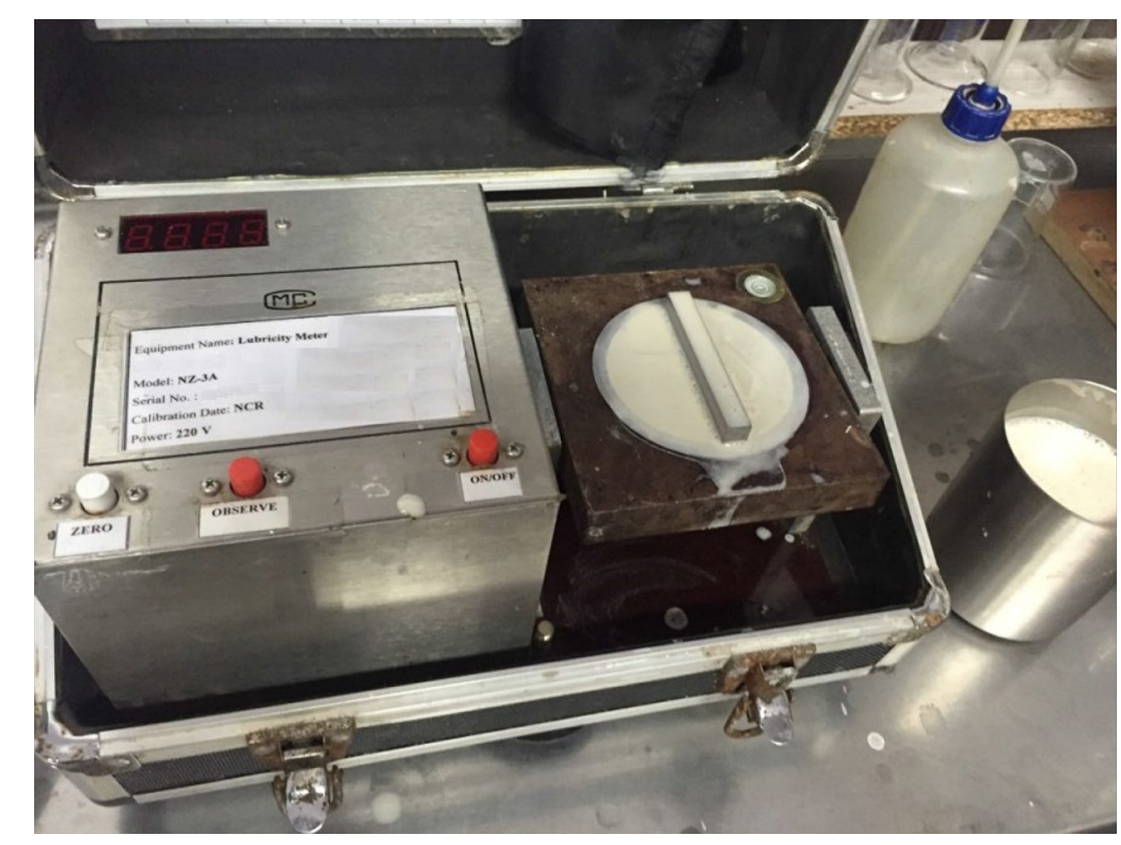

\begin{tabular}{lllllll}
\hline Lubricant type & Form & Color & Specific gravity & $\begin{array}{l}\text { Resistance to } \\
\text { deformation } \\
(\mathrm{PSI})\end{array}$ & $\begin{array}{l}\text { thermal } \\
\text { stability } \\
\left({ }^{\circ} \mathrm{F}\right)\end{array}$ & $\begin{array}{l}\text { Cost }(1 \\
\text { sack=55 } \\
\text { lbs) }\end{array}$ \\
\hline Glass bead 100 & Spherical solid bead & Clear & $2.3-2.6$ & 10,000 & 500 & $45 \$$ \\
Glass bead 600 & Spherical solid bead & Clear & $2.3-2.6$ & 10,000 & 500 & $47 \$$ \\
\hline
\end{tabular}


Table 5 Coefficient of friction of all mud samples before and after adding liquid and solid lubricants in different concentrations

\begin{tabular}{|c|c|c|c|c|c|c|c|c|c|}
\hline \multicolumn{9}{|c|}{ Coefficient of friction (CoF) for the drilling fluid with different concentration of glass beads } & \\
\hline \multirow[t]{2}{*}{ Sample } & \multirow[t]{2}{*}{ Concentration by wt } & \multirow{2}{*}{$\begin{array}{l}\text { Without } \\
\text { glass bead }\end{array}$} & \multicolumn{3}{|c|}{ Glass bead 100} & \multicolumn{3}{|c|}{ Glass bead 600} & \\
\hline & & & $0.1 \mathrm{ppb}$ & $0.3 \mathrm{ppb}$ & $1 \mathrm{ppb}$ & $0.1 \mathrm{ppb}$ & $0.3 \mathrm{ppb}$ & $1 \mathrm{ppb}$ & \\
\hline \multirow[t]{3}{*}{ Lubricant A+diesel } & $1 \% A+4 \% D$ & 0.08 & 0.06 & 0.06 & 0.04 & 0.05 & 0.05 & 0.04 & \multirow{11}{*}{$\begin{array}{l}\text { Coefficient } \\
\text { of friction } \\
\text { (CoF) }\end{array}$} \\
\hline & $2 \% A+3 \% D$ & 0.07 & 0.05 & 0.04 & 0.03 & 0.04 & 0.03 & 0.03 & \\
\hline & $3 \% A+2 \% D$ & 0.06 & 0.05 & 0.04 & 0.03 & 0.03 & 0.03 & 0.03 & \\
\hline \multirow[t]{3}{*}{ Lubricant B+diesel } & $1 \% B+4 \% D$ & 0.09 & 0.08 & 0.07 & 0.06 & 0.08 & 0.07 & 0.06 & \\
\hline & $2 \% B+3 \% D$ & 0.08 & 0.06 & 0.05 & 0.05 & 0.06 & 0.05 & 0.04 & \\
\hline & $3 \% B+2 \% D$ & 0.07 & 0.04 & 0.04 & 0.03 & 0.04 & 0.04 & 0.03 & \\
\hline \multirow[t]{5}{*}{ Diesel } & $1 \% \mathrm{D}$ & 0.24 & 0.24 & 0.24 & 0.10 & 0.24 & 0.10 & 0.08 & \\
\hline & $2 \% \mathrm{D}$ & 0.11 & 0.02 & 0.11 & 0.09 & 0.11 & 0.09 & 0.08 & \\
\hline & $3 \% \mathrm{D}$ & 0.09 & 0.09 & 0.08 & 0.07 & 0.09 & 0.08 & 0.07 & \\
\hline & $4 \% \mathrm{D}$ & 0.08 & 0.08 & 0.08 & 0.06 & 0.08 & 0.07 & 0.06 & \\
\hline & $5 \% \mathrm{D}$ & 0.07 & 0.07 & 0.06 & 0.05 & 0.06 & 0.06 & 0.04 & \\
\hline
\end{tabular}

Fig. 3 Coefficient of friction of $0.1,0.3$ and $1 \mathrm{lb} / \mathrm{bbl}$ glass bead $100 \&$ glass bead 600 as solid lubricants mixed with mud samples consist of $1-5 \%$ diesel oil as only liquid lubricant
0.3

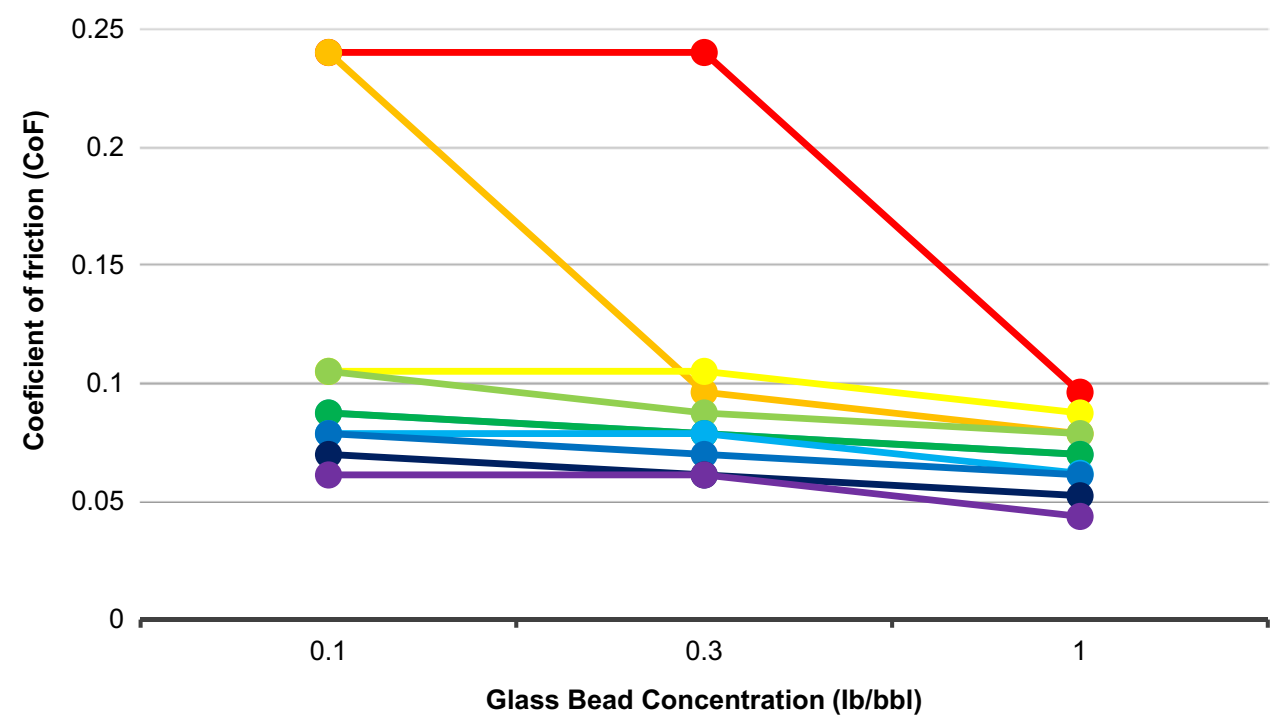

Glass Bead Concentration (lb/bbl)
After adding lubricants to mud samples, mud properties are measured such as funnel viscosity, plastic viscosity $(\mathrm{PV})$, yield point (YP) and filter loss to assure they are in good range. It is observed that no major change in fluid properties occurs after adding liquid lubricants at a specified concentration and all mentioned properties were in good range.

According to the drilling mud program, it is not used Lub A or Lub B at a concentration of $5 \mathrm{Vol} \%$ alone because of the costs. Dropping crude oil prices have pushed oil exploration and drilling projects below the break-even point. Diesel oil is much less expensive than these two commercial liquid lubricants so that we use diesel oil mixed with Lub A or Lub B. The most common concentration of liquid lubricants is the combination of Lub A 3\% and diesel oil 2\% and it can reduce Drilling fluid costs significantly. The use of liquid lubricants with volumes more than $5 \mathrm{Vol} \%$ in the mud system makes a 
Fig. 4 Coefficient of friction of $0.1,0.3$ and $1 \mathrm{lb} / \mathrm{bbl}$ glass bead $100 \&$ glass bead 600 as solid lubricants mixed with mud samples consist of diesel oil and Lub $A$ as liquid lubricants
0.1

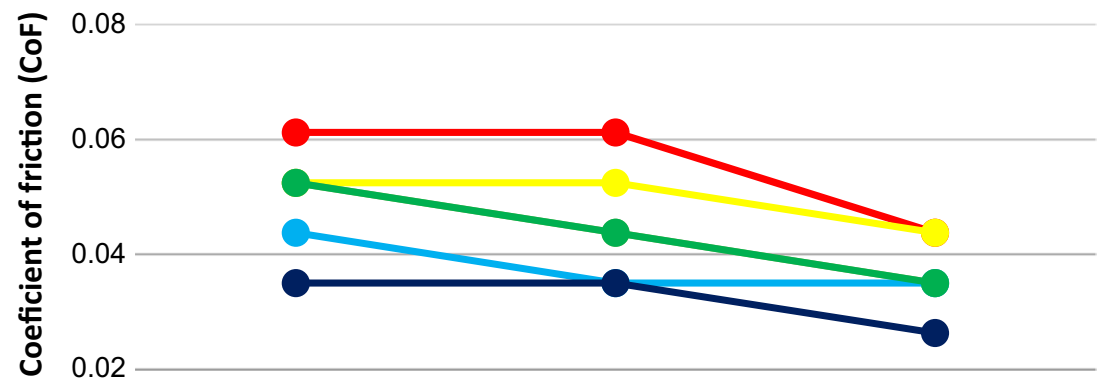

Fig. 5 Coefficient of friction of $0.1,0.3$ and $1 \mathrm{lb} / \mathrm{bbl}$ glass bead $100 \&$ glass bead 600 as solid lubricants mixed with mud samples consist of diesel oil and Lub B as liquid lubricants

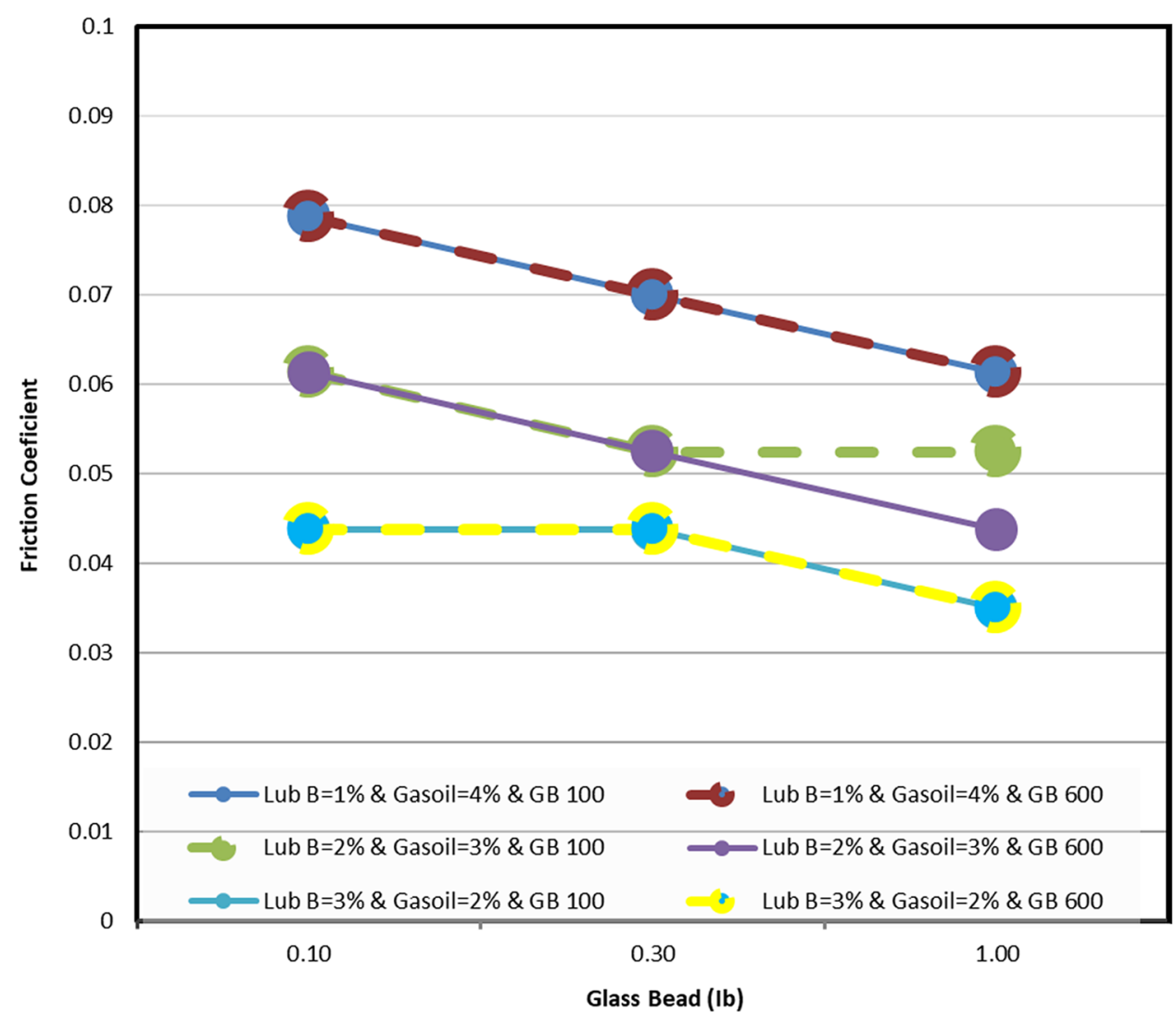

negative effect on mud properties and causes a sudden increase in drilling fluid rheology (PV \& YP) that is called "jumping" (Table 6). Note that high amount of yield point leads to high-pressure losses while the drilling fluid is being circulated.
Results have shown that the friction coefficient was obviously decreased after added with Glass Bead as a solid lubricant. From the Table 5 and Fig. 6 , it is observed that the minimum friction coefficient is related to the $3 \%$ Lub A and $2 \%$ diesel oil (0.0612) which can be obtained by 
Table 6 Design of glass bead pill concentrations

\begin{tabular}{|c|c|c|c|}
\hline \multirow{2}{*}{$\begin{array}{l}\text { Drilling fluid } \\
\text { properties }\end{array}$} & \multicolumn{3}{|c|}{ Liquid lubricants } \\
\hline & Viscodity (sec) & YP (lb/100 ft) & $\mathrm{PV}(\mathrm{CP})$ \\
\hline 44 & 21 & 15 & 1\% Lub A \\
\hline 44 & 21 & 15 & $2 \%$ Lub A \\
\hline 44 & 21 & 15 & $3 \%$ Lub A \\
\hline 45 & 21 & 16 & $4 \%$ Lub A \\
\hline 45 & 21 & 17 & $5 \%$ Lub A \\
\hline 46 & 23 & 21 & $6 \%$ Lub A \\
\hline 48 & 24 & 24 & 7\% Lub A \\
\hline 49 & 26 & 28 & $8 \%$ Lub A \\
\hline 44 & 21 & 15 & 1\% Lub B \\
\hline 44 & 21 & 15 & $2 \%$ Lub B \\
\hline 44 & 21 & 15 & 3\% Lub B \\
\hline 45 & 21 & 16 & 4\% Lub B \\
\hline 45 & 21 & 17 & $5 \%$ Lub B \\
\hline 46 & 25 & 20 & $6 \%$ Lub B \\
\hline 48 & 26 & 24 & 7\% Lub B \\
\hline 51 & 29 & 30 & $8 \%$ Lub B \\
\hline 44 & 21 & 15 & 1\% Gasoil \\
\hline 44 & 21 & 15 & $2 \%$ Gasoil \\
\hline 44 & 21 & 15 & 3\% Gasoil \\
\hline 45 & 21 & 16 & 4\% Gasoil \\
\hline 45 & 21 & 17 & $5 \%$ Gasoil \\
\hline 46 & 24 & 22 & $6 \%$ Gasoil \\
\hline 48 & 24 & 24 & 7\% Gasoil \\
\hline 49 & 26 & 27 & $8 \%$ Gasoil \\
\hline
\end{tabular}

liquid lubricants. But it can reduce the friction coefficient to 0.0262 by using $1 \mathrm{lb}$ per barrel of Glass Bead 100 as solid lubricants. The results depict that solid lubricants can utilize in some operational needs, where liquid lubrication is impractical. Additionally, reducing the use of liquid lubricants by replacing them with solid lubricants is possible without having a negative effect on drilling fluid rheology. As shown in Table 5, the coefficient of friction when using 5 vol\% of diesel oil as a liquid lubricant is 0.0699 , which can be obtained with the same coefficient of friction with $3 \%$ diesel oil and $1 \mathrm{lb}$ per barrel Glass Bead, which reduces the environmental pollutions caused by diesel oil. Solid lubricants are environmentally friendly in terms of cuttings disposal.

\subsection{Operational summary}

Oil well drilling is done by rotating and putting weight on a drilling bit to make a hole. Weight on bit (WOB) is the amount of downward force exerted on the drill bit and is normally measured in thousands (kilo pound) and RPM is drill string (drill pipe) rotation speed (round per minute). The rate of penetration (ROP), also known as penetration rate or drill rate, is the speed at which a drill bit breaks the rock under it to deepen the borehole. It is normally measured in feet per minute or meters per hour. The rate of penetration (ROP) that can be achieved with a specific bit is determined by the aggressiveness of its design, the weight on bit (WOB) applied, the revolution per minute (RPM) and the rock strength. When the RPM or WOB are increased, the rate of penetration (ROP) should increase proportionately. If the ROP does not increase proportionately to WOB, it is because something is making the rock cutting process inefficient (excessive torque ad drag). Reduction in torque and drag leads to ROP increase. ROP increase will lead to reduction in time and cost of the well.

Mud logging is the creation of a real-time detailed record (well log) of a borehole by examining the cuttings of rock brought to the surface by the circulating drilling medium (most commonly drilling mud). Other real-time drilling parameters that may be compiled include, but are not limited to; rate of penetration (ROP) of the bit), pump rate (quantity of fluid being pumped), pump pressure, weight on bit, drill string weight, rotary torque, RPM (Revolutions Per Minute), SPM (Strokes Per Minute) mud volumes, mud weight and mud viscosity. This information is usually obtained by attaching monitoring devices to the drilling rig's equipment.

As stated earlier, the results depict that solid lubricants can utilize in some operational needs where liquid lubrication is impractical. After favorable results were achieved in the laboratory, the project team decided to use solid lubricant as Glass Bead pill periodically at the concentration of $3 \mathrm{lb} / \mathrm{bbl}$ GB $100 \& 3 \mathrm{lb} / \mathrm{bbl}$ GB 600 .

When high drag was experienced during horizontal drilling especially in slide mode even using liquid lubricant at a concentration of $5 \% \mathrm{vol}$ in mud system, pumping Glass Bead pills had a direct impact on reducing drag which leads to increase ROP from $0.3 \mathrm{~m} / \mathrm{hr}$ to $1.1 \mathrm{~m} / \mathrm{hr}$. It can significantly reduce drilling costs and improve the economics of drilling projects.

Drilling parameters were monitored by mud logging service but ROP is the best indication of the performance. According to Fig. 7, after pumping the pill in the hole at the depth of $4020 \mathrm{~m}$, ROP was obviously improved. The pill circulated out of bit at 20:51 O'clock and mud logging graph showed that ROP start to increase at this time and it decreased when the pill passed from bottom hole assembly (BHA) in annulus but not as low as ROP before pumping. Generally, it would appear that some of the glass beads become embedded in the filter-cake to reduce the torque and drag forces and ultimately improve ROP.

During this phase, the project team made several design improvements, particularly in work instruction of Glass Bead pill as follow: 
Fig. 6 Coefficient of friction of mud samples consist of diesel oil, and Lub A and Lub B as liquid lubricants
Fig. 7 Mud Logging Graph for ROP and other drilling parameters before and after pumping glass bead pill
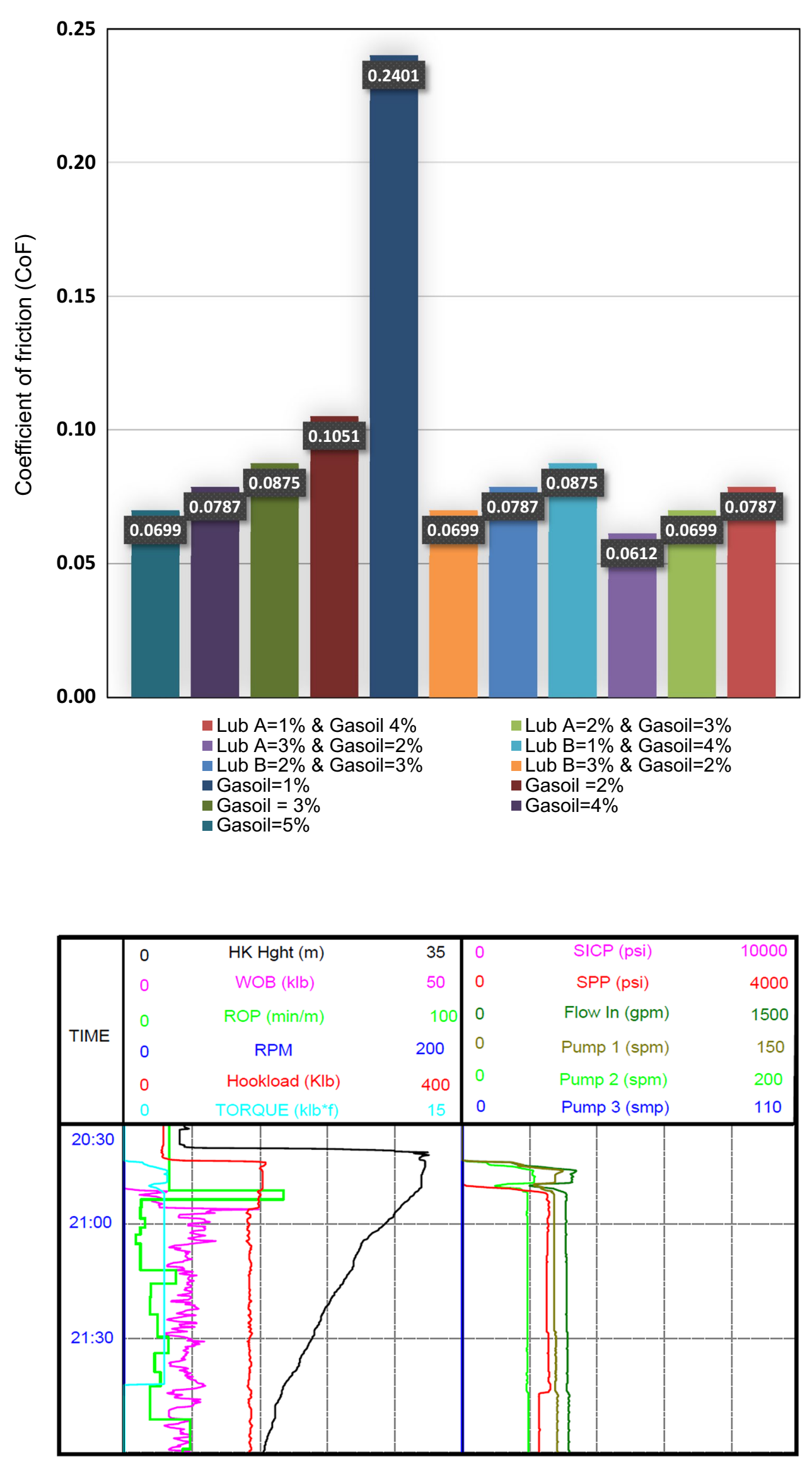

SN Applied Sciences 
- Spot (Place) 30 barrels of the pill with the viscosity in the range of 60-65 s around the BHA. Then, turn off the pumps and move the drill string up and down for $10 \mathrm{~min}$ until the glass beads embed in mud cake or settle in the low side of the hole. Then set the tool face and begin to slide the horizontal drilling operations. Since then, ROP is monitored and recorded.

Note: We made many pill samples with a different viscosity in laboratory and glass bead settling rate was monitored. From the detected results, it was founded that a pill with a viscosity of $60-65 \mathrm{~s}$ has the best performance. The pill viscosity should be enough to carry the glass beads and should not be too high to suspend all of them and prevent the beads to settle into low side of the hole.

- All the drilling parameters before and after the pumping of the pill should be recorded including WOB, Revolution Per Minute (RPM), Gallon Per Minute (GPM), hole

Table 7 Design of glass bead pill concentrations

\begin{tabular}{llll}
\hline $\begin{array}{l}\text { Course } \\
(800-1000)\end{array}$ & $\begin{array}{l}\text { Medium } \\
(400-600)\end{array}$ & Fine (100-200) & $\begin{array}{l}\text { Pill concen- } \\
\text { tration (lb/ } \\
\text { BBI) }\end{array}$ \\
\hline 3 & 3 & 0 & 6 \\
2 & 2 & 2 & 6 \\
3 & 3 & 2 & 8 \\
4 & 4 & 0 & 8 \\
4 & 4 & 2 & 10 \\
6 & 4 & 0 & 10 \\
5 & 5 & 2 & 12 \\
8 & 4 & 0 & 12 \\
\hline
\end{tabular}

inclination, Glass bead size and the lithology of the formation.

- When pumping the pill, it is necessary to calculate and record the precise time of pumping pill, the time it takes out of the bit and the time it takes to exit the well.

- It is necessary that all drilling parameters should be the same as possible before and after pumping the pill so that a proper comparison of the effect of the pill on the ROP can be made

- Glass Bead content used at first step is $3 \mathrm{lb}$ of GB 100 and $3 \mathrm{lb}$ of GB 600. If there is any improvement in ROP, use the other glass bead contents according to the Table 7.

To compare the effect of pumping Glass bead pill, a statistical result of the drilling data in the hole section of $6 \frac{1}{8}$ inch before and after pumping Glass Bead pill is shown in Table 8. From the Table 8, it can be understood the effect of solid lubricant.

After favorable results were achieved in this well, this procedure was applied for next 13 wells in this filed and all the $6 \frac{1}{8}$ inch hole sections were drilled to target successfully. The average increased ROP was $160 \%$ and according to directional driller observations, controlling WOB throughout the sliding was easier after pumping the pills. In many cases, slide drilling was impossible due to the high amount of drag (Fig. 8).

Apart from these above-mentioned advantages, no string hang up, pressure up and stalling has been recorded during drilling. Frequent stalling can damage the stator components of the motor depending on the amount of the weight transferred.

Table 8 Drilling parameters and other data before and after pumping glass bead pill

\begin{tabular}{|c|c|c|c|c|c|}
\hline \multicolumn{3}{|l|}{ Before pumping data } & \multicolumn{3}{|c|}{ After pumping data } \\
\hline Time & $15: 51$ & $16: 51$ & Time pill pump & $17: 00$ & $17: 18$ \\
\hline Depth (m) & 4025 & 4025.2 & Depth & $4025.2 @ 18: 00$ & $4027.2 @ 19: 13$ \\
\hline WOB (K Ib) & $15-20$ & & WOB & $15-20$ & \\
\hline Motor RPM & 220 & & Motor RPM & 220 & \\
\hline Flow Rate (gal/min) & 210 & & GPM & 210 & \\
\hline Inclination (degree) & 90.6 & & Inclination & 90.6 & \\
\hline Dogleg (degree/100 ft) & 2 & & Dogleg & 2 & \\
\hline Lithology & Limestone & & Lithology & Limestone & \\
\hline \multirow[t]{5}{*}{$\mathrm{ROP}(\mathrm{m} / \mathrm{hr})$} & 0.2 & & ROP & 1.65 & \\
\hline & & & Time pill out bit & $17: 52$ & \\
\hline & & & Time pill out well & 19:10 & \\
\hline & & & Pill viscosity & $60-65$ & \\
\hline & & & Glass bead type & $3 \mathrm{lb}$ GB $100+3 \mathrm{lb}$ GB 600 & \\
\hline
\end{tabular}


Fig. 8 ROP Increase for each well

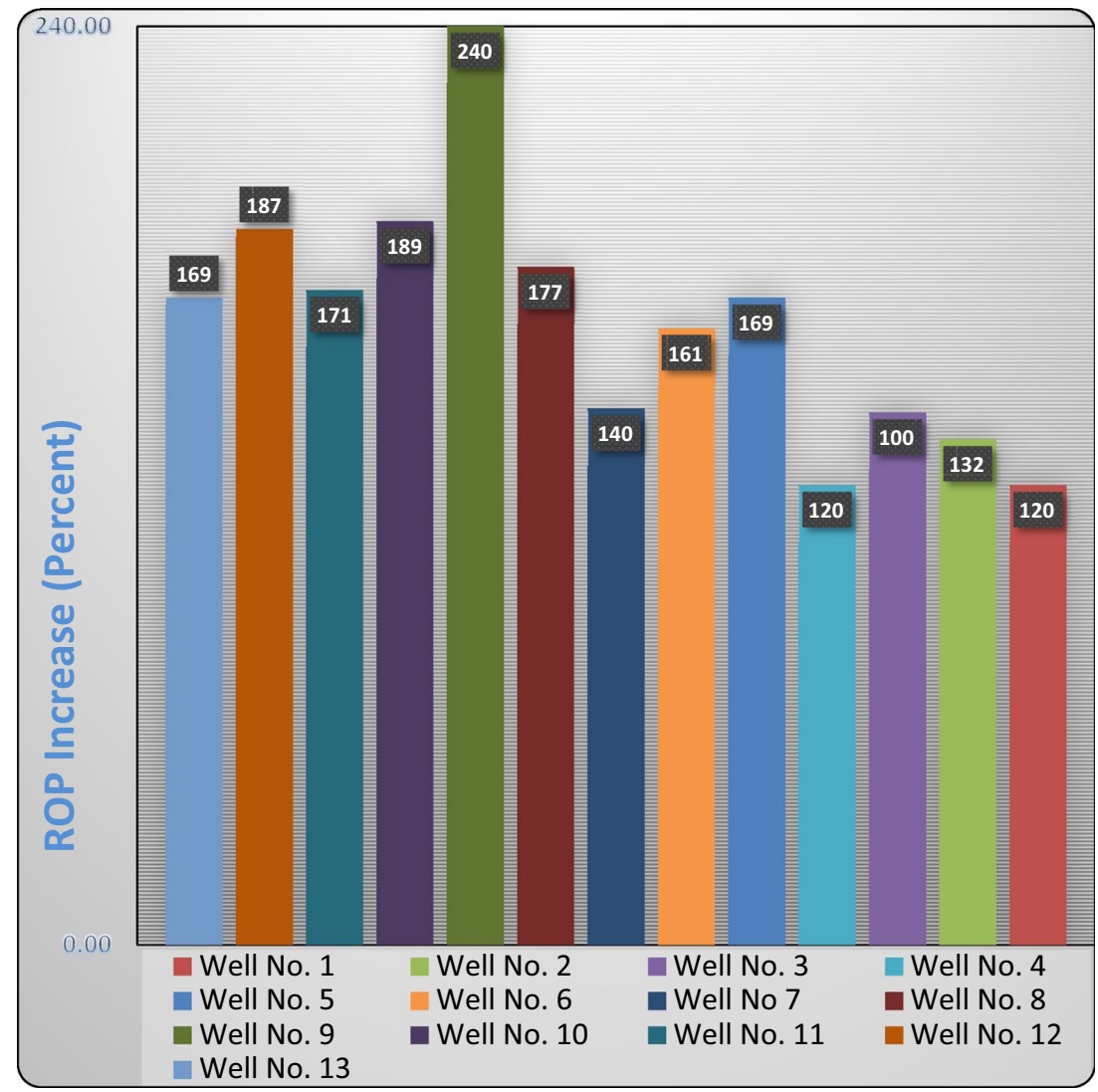

\subsection{Lubricant cost comparisons}

Influenced by the international oil price, the drilling industry is suffering in a hard time. Drilling fluid costs are estimated to gulp about $20 \%$ of the total drilling cost of a well.

As stated earlier, typically a 3\% commercial lubricant (A or $B$ ) and $2 \%$ diesel oil are used as liquid lubricants during directional and horizontal drilling of $8 \frac{1}{2}$ inch and $6 \frac{1}{8}$ inch holes. Since lubricant $A$ has a higher quality than lubricant $B$, it is selected as the usual lubricants for comparison of cost and performance. As shown in Table 5, the coefficient of friction of this composition is $0.0612\left(\mathrm{~K}_{\mathrm{f}}=0.0612\right)$. This friction coefficient is equivalent to a composition of $5 \%$ diesel oil and $0.3 \mathrm{lb} / \mathrm{bbl}$ of Glass bead ( 5 vol\% Gasoil + 0.3 $\mathrm{lb} / \mathrm{bbl} \mathrm{GB})$. Hence, it is a good candidate to compare the costs of lubricants.

In these 22 wells, an average of 2900 and 1,000 barrels of mud were made in $8 \frac{1}{2}$ inch and $6 \frac{1}{8}$ inch respectively. By knowing the price of each material and volume of mud to be prepared, we can compare the costs of solid and liquid lubricants with the same performance.

Results of calculations showed that instead of using the usual 3\% liquid lubricant $(A)$ and $2 \%$ diesel oil, diesel oil as the only liquid lubricant beside the Glass Bead 600 can be used at a concentration of $0.3 \mathrm{lb}$ per barrel, which will have the same and even better performance while reduces the cost of drilling fluid in the 8.5 inch hole section by $72 \%$ and in the hole section 6.125 inches by 25\% (Fig. 9).

\section{Conclusions}

- The addition of Glass Bead as a solid lubricant can improve the performance of water-based drilling fluids as evidenced by improvement in ROP up to $240 \%$ (average ROP: 160\%).

- By the use of solid lubricants, the costs of drilling fluid can be reduced in the 8.5 -inch hole section by $72 \%$ and in the hole section 6.125 inches by $25 \%$.

- The use of liquid lubricants with volumes more than 5 Vol\% in the mud system makes a negative effect on mud properties and causes a sudden increase in drilling fluid rheology (PV \& YP). Therefore, no more than 5 to 6 percent of liquid lubricants can be used to reduce friction coefficient. This limitation, along with the issue of lubrication, leads us to use solid lubricants. 
Fig. 9 Comparison of the costs of solid and liquid lubricants in 22 wells, for mud concentrations, promoting a minimum of friction

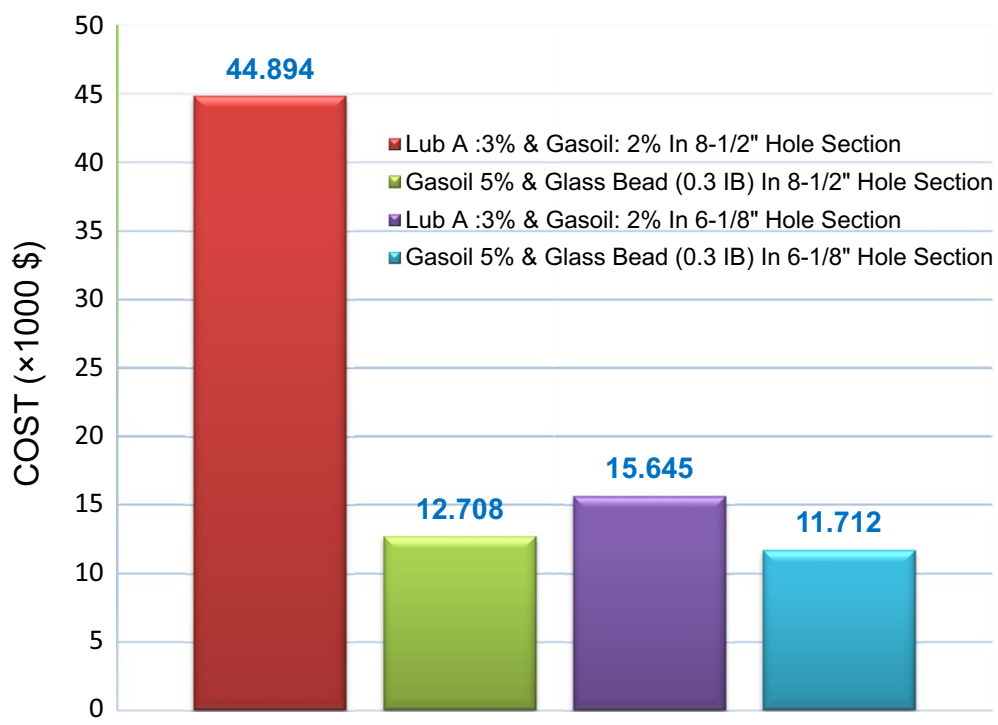

\section{Compliance with ethical standards}

Conflict of interest On behalf of all authors, the corresponding author states that there is no conflict of interest.

\section{Reference}

1. Bird J, Garrett C (1996) Co-polymer beads reduce friction in horizontal wells. Pet Soc Canada. https://doi.org/10.2118/96-09-GE

2. Foxenberg WE, Ali SA, Long TP, Vian J (2008) Field experience shows that new lubricant reduces friction and improves formation compatibility and environmental impact. Soc Pet Eng. https ://doi.org/10.2118/112483-MS

3. Growcock FB, Frederick TP, Reece AR, Green GW, Ruffin MD (1999) Novel lubricants for water-based drilling fluids. Soc Pet Eng. https://doi.org/10.2118/50710-MS

4. Holand J, Kvamme SA, Omland TH, Saasen A, Taugbol K, Jamth J (2007) Lubricant enabled completion of ERD well. Soc Pet Eng. https://doi.org/10.2118/105730-MS

5. Jha PK, Mahto V, Saxena VK (2013) Study the rheol ogical and filtration properties of oil-in-water emulsion for its application in oil and gas well drilling. J Pet Engg Technol 3:25-30

6. Kumar AS, Mahto V, Sharma VP (2003) Behaviour of organic polymers on the rheological properties of Indian bentonite-water based drilling fluid and its effect on formation damage. Indian J Chem Technol 10:525-530

7. Kutlu B (2013) Rheological properties of drilling fluids mixed with lightweight solid. Soc Pet Eng. https://doi. org/10.2118/167619-STU
8. Knox D, Jiang $P$ (2005) Drilling further with water-based fluids-selecting the right lubricant. Soc Pet Eng. https://doi. org/10.2118/92002-MS

9. Mohammadi MK, Nowtarki KT (2015) A case study on the successful application of solids lubricants in directional and horizontal drilling operations to reduce torque and drag and improve ROP in one of the carbonate oil reservoirs. Soc Pet Eng. https://doi.org/10.2118/176473-MS

10. McCormick JE, Chiu TF (2011) The practice and evolution of torque and drag reduction: theory and field results. Soc Pet Eng. https://doi.org/10.2118/147100-MS

11. Melekhin AA, Chernyshov SE, Blinov PA, Nutskova MV (2016) Study of lubricant additives to the drilling fluid for reducing the friction coefficient during well construction with rotary steerable system. Oil Ind J 10:52-55

12. Haddad M, AL-Aleeli AR, Zaheer B (2017) Drilling of challenging erd wells with water-based mud: how to sinificantly reduce torque and drag by new generation lubricant. Soc Pet Eng. https ://doi.org/10.2118/188796-MS

13. Diaz N, Paila P, Kirby C (2018) Successful implementation of torque and drag management techniques in high departure wells is the key to safely reach wells planned depth in offshore artificial Islands. Soc Pet Eng. https://doi.org/10.2118/19270 9-MS

14. Li W, Zhao X, Peng H (2016) A novel environmentally friendly lubricant for water-based drilling fluids as a new application of biodiesel. Soc Pet Eng. https://doi.org/10.2118/180565-MS

Publisher's Note Springer Nature remains neutral with regard to jurisdictional claims in published maps and institutional affiliations. 